\title{
Shadow Puppets Performance of Yogyakarta through its Visual Language
}

\author{
Ika Ismurdyahwati \\ Universitas PGRI Adi Buana Surabaya, \\ J1. Ngagel Dadi III-B/37 Surabaya 60245, Indonesia \\ Email: ika_sritb@yahoo.com
}

\begin{abstract}
The shadow puppet performance conveys its story to the viewers through its visual language. The aim of this research is to reveal the visual language of the gesture effects in the shadow images of the shadow puppet performance of Yogyakarta. Visual language stands for the representative images that are similar to the original objects and the way to draw it. In the case of shadow puppet performance of Yogyakarta, Central Java, Indonesia, the way to draw the images correlated to the space-time-plane system of drawing. The space-time-plane system has the characteristic to have multiple angles, distances and moments. The results of this research were each movements of the main puppet character determine it own body language.
\end{abstract}

Keywords: shadow puppets; visual language; performance; movement; gesture; images; modern innovation.

\section{$1 \quad$ Introduction}

Shadow Puppet Theater is the oldest form performance of motion picture storytelling. Compared to the modern form of motion pictures, such as film, are about a hundred years old, and television was first invented only about sixty years ago, the roots of shadow puppetry go back thousands of years into prehistory [1]. It even predates visual language. We can imagine Stone Age people, living in caves during the last Ice Age, sitting around open campfires fires that make fascinating shadows dance on the wall. Soon they would have discovered out how to use their bodies, hands or simple figures made from sticks, feather and animal skins, to help them telling the old stories of their family and clan.

This record tells us some important information about how early forms of shadow puppets might have been used in religious ceremonies as a way for the living to communicate with the world of the spirits [2]. It was also used by priests and monks to transmit religious stories and myths to population who did not know how to read. Even today, some of these old forms of religious shadow puppetry have survived in southern Asia, especially in India and in Indonesia. There the shadow puppets perform scenes from great religious epics, such as the Mahabarata and the Ramayana [3]. On the islands of Java and Bali, especially,

Received July $5^{\text {th }}, 2010$, Revised October $29^{\text {th }}, 2013$, Accepted for publication November $8^{\text {th }}, 2013$

Copyright () 2013 Published by LPPM ITB, ISSN: 1978-3078, DOI: 10.5614/itbj.vad.2013.4.1.4 
the "wayang kulit" as it is called, is a widely popular form of entertainment that been developed to the highest artistic standards.

Shadow puppets performance of Yogyakarta, in central Java Indonesia, each role type has a unique style of acting and movement, a particular identifying color and styling to the costumes, headdresses and facial make-up [4]. The design of the shadow figures reflects these roles types also, so that the moment they appear on the screen, the audience knows from the face patterns, dress and props exactly who they are, their age, sex, social rank, profession and personality. Acting styles are also shared by the live opera and the shadow puppet figures. When they first enters the stage, a shadow figure or human will first freeze in a quick pose, and adjust their sleeves, headdress or beard. This allows the audience a chance to "read" their character and also to "greet" the actor with a round of applause. It is amazing to see how the stylized movements and gestures, freezes and poses that heighten dramatic moments translated from the 3-dimensional live actors to the 2-dimensional shadow puppet figure, without losing any of its force and clarity.

The study upon the performance of Puppet Theater in Yogyakarta would be focused on shadow puppets from the gesture effects/motion effects of shadow images facing a backlit screen. Becker, A.L [2], in the puppet theater, the backlit screen is an essential element of the performance. In the gesture effects from shadow puppet to be found is visual language movement in part from storytelling aspect. Shadow play and storytelling are the ancient art of conveying events in words, images (moving images), and sound. Stories have probably been shared in every culture and in every land as a means of entertainment, education, preservation of culture and to instill knowledge and values morals [5]. The title of the research to be proposed is "The Shadow Puppets Performance of Yogyakarta Through its Visual Language", this research focused on the shadow images from the gesture effects to be found is visual language. Mean of the visual language its representative pictures/images similar with original objects, and the way to draw it. In visual language we have image and grammar, in 'image' there is Image Content (the object drawn) and Image Way (the way to draw it). Moving images from gesture effects in shadow puppet it's the way to draw it, and produces tells a story.

\section{Methods of Research}

This research is qualitative, in the field of cultural studies. Because the culture here, regarded as the product of human reason, a puppet performances as objects of research. While the study subjects using the language arts, as well as data collection methods and techniques. Purpose is to uncover the meaning of images in the form of 'motion' shadow puppets, in conjunction with a variety of 
values and moral messages are conveyed in the form of shadow puppet performances. Research stages, namely: data collection, classification, and analysis [6].

\section{Visual Language as Theoretical Basis}

The researches apply the visual language as theoretical basis and analysis study. In word language, each ethnic/nation invented a different word for the same object: horse (English), paard (Dutch), cavallo (Italian), cheval (French), kuda (Indonesian), jaran (Javanese), jara (Flores), kabayo (Tagalog), uma (Japanese). In representative pictures visual language, a drawing of the same object by one ethnic/nation can be recognized by the other. The fascinating aspect in visual language was not lay upon the drawing or the object that were draw on by the ethnic/nation, but rather in the way to draw it. In the word language, we apply the words and grammars; in the visual language we apply the image and its grammars also. The visual language concerns two aspects, the Image Content (the object drawn) and Image Way (the way to draw it) [7].

Some characteristic in the visual language can be interpreted, as follows:

1. An object that were drawn with dynamic form and expressive contour, has the meaning that the object were moving (keep in mind that one picture having a visual language similar to a 'movie scene', not as a still picture of a moving object.).

2. An object that was drawn with a static contour has the meaning that the object was relatively static. For example, if an ostrich with two legs is drawn with 3 bodies and 6 neck-heads, we cannot interpret the drawing as a mystical mysterious creature, rather than the drawing tells us that the ostrich is in a process of revolving from being caught by a lasso.

3. We can also identify a very important object in the scene by the way it drawn that were bigger from its surroundings.

4. An important object that had to be recognized would be drawn from the most characteristic view.

5. If an incident inside a body or a building is important than it is drawn as Space-Time-Plane (STP) system, with its characteristic that the drawing is being 'shot' from several angel, several distance, and several time.

The picture drawn with STP system become a sequence since it has a time dimension and usually consists of several movie-scenes. One picture not only describes what object were drawn, but also tells a story. This characteristic was very different from our modern Naturalistic-Perspective-Frozen moment (NPF) system of drawing. In The NPF system, the drawing was shot only from single angle, distance, and time. The picture became a scene of a still picture that were 
froze in an instance, and then framed, and only describes the objects that were drawn in the picture [8].

Table 1 Picture and scene of the shadow movement.

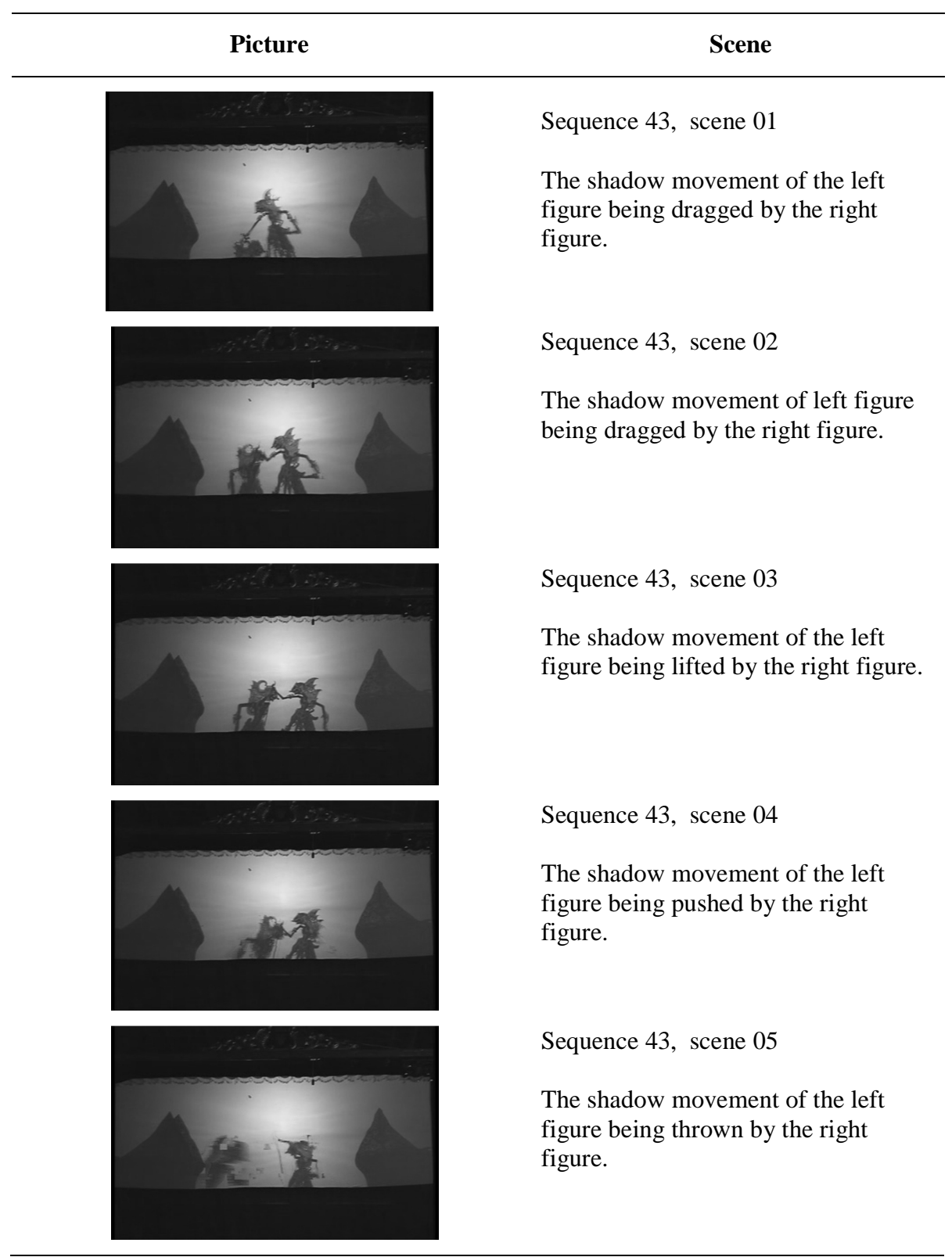


In the STP system, there were two kinds of grammars were existed: the Inner Grammar and Outer Grammar. The Inner Grammar is how we compose a picture from several images and in its own image way, so that the picture could convey a story. Outer grammar is the connection between different inner grammar of one picture and another or the 'bridge'. The Outer Grammar makes a series of picture could tell a longer story since it has a continuation. The shadow puppets performance of Yogyakarta has the gesture effects/motion effects as outer grammar. The pictures become a sequence since it has a time dimension and usually consist of several movie-scenes.

The aim of this research is to analyze the results of my previous research, to validate the methods have been used to get the results, explain the criteria for checking the validity and accuracy of the achievements from shadow puppet 'movement'. Hopefully the results would increase the vocabulary of visual language.

The separations between each shape and time in shadow play performance were marked by the mountainlike figure called 'gunungan/kekayon'. The two 'gunungan's symbolizing the universe was stuck on the right and lef stage formed a manner of frame for the play. Each scene in the performance were limited by 'gunungan wayang', similar to the way animation film framed the scene, sequence by sequence.

The image serial formed by the puppet movement create the visual language vocabulary that possibly would enhance the modern animation expressions [5]. The scene by scene of working process upon the visual language presented in the Table 1 .

\section{Modern Innovations: How to 'Read' Shadow Images from the Gesture Effects to be Found is Visual Language}

Today, even with film, television and computers, and all kinds of sophisticated animation techniques, the ancient forms of shadow puppetry have not totally disappeared. It has adapted modern materials and methods, but the essence of the art form is unchanged since the day that the Sri Sultan in Yogyakarta sat down in astonishment at seeing the ghost of his puppeteer in creativities from shadow puppet 'movement'.

Mixing and merging all these elements together have given the shadow artist the freedom to create large-scale moving image spectacles that are closer to animated film than to traditional shadow performance. Using an overhead projector as a light source, instead of a light bulb can magnify an object or puppet figure placed on its flat, glass table-top of the projector to create an 
image large enough to fill a huge movie screen [9]. A very small figure only a few inches tall can be transformed into a gigantic image. Larger scale shadow images, such as those created on an overhead projector, can be easily integrated into other forms of live theater performance.

In the Traditional concept, the audience had a chance to "read" their character and also to "greet" the actor. This character is similar the way the viewers watch the television, that an object is drawn with dynamic form and expressive contour; it means that the object is moving (that one picture having a visual language is like a 'movie scene'). If an object is important to be recognized, than it wall be drawn from the most characteristic view. If an incident inside a body or a building is important than it is drawn as Space-Time-Plane (STP) system, with its characteristic that the drawing is being 'shot' from several angel, several distance, and several time.

People of today can get pleasure from the shadow puppet performance with relatively small arrangement. We can seek the similarity between shadow puppet performance and modern and animation film on how the serial images presented to the audiences.

\section{Conclusions}

The study already established that the 'movement' aspect of Purwa of Yogyakarta's style, the data concerning the detailed 'movements' were identified. Each of the detailed movement has its own story. Each movement of the main characters determines its own body language.

Analyze here the results expected and the ones achieved, outline the methods used to get the results, explain the criteria for checking the validity and accuracy of the achievements from shadow puppet 'movement', and tell a story. So to increase vocabulary visual language from study that the 'movement' the shadow puppets performance of Purwa of Yogyakarta.

Shadow puppets performance of Purwa of Yogyakarta has a particular way to draw it and this has its space-time-plane system of drawing, which is the spacetime-plane system in multiple angle/distance/moment. Each movement of the main characters determines its own body language. We can read the space-timeplane system picture's movement its visual language, so we can grasp the story to similar to watch at the television.

The modern people can enjoy the shadow puppet performance through the visual language in the same way as in the animation film images. 
To more easily enjoy the performance of shadow puppets in the form moving shadow puppets, it needs picture languages like animated film images.

\section{Reference}

[1] Agung, J.P.T. 1984. Lordly Shades. Wayang Purwa Indonesia. Published through the Generosity of Bapak Probosutedjo, pp. 48-49.

[2] Becker, A.L. 1979. Text-Building, Epistemologi, and Aesthetics in Javanese Shadows Theater.

[3] Dutt, R.C. 1976. The Ramayana \& The Mahabarata (Condensed English into verse). Dent: London Everyman's Library. Dutton: New York, pp. 37-39.

[4] Long, R. 1979. Javanese Shadow Theater. Movement and Characterization in Ngayogyakarta Wayang Kulit, Umi Research Press, Ann Arbor, Michigan, pp. 21-102; Appendix: 55, 62.

[5] Becker, A.L. \& Yengoyan, A.A. (ed.). 1979. The Imagination and Reality: Essays on Southeast Asian Coherence System, Norwood, New Jersey: Ablex Publication, pp. 85-125, 218-223.

[6] Koeshandari, I. 2007. Pergelaran Bayangan Wayang Kulit Purwa dalam Kajian Bahasa Rupa 'Gerak' (Lakon Parta Krama Gaya Yogyakarta), Disertation, Program Fine Arts and Design, Institute Technology of Bandung.

[7] Tabrani, P. 2005. Bahasa Rupa, Bandung, Kelir Publications.

[8] Madsen, P.R. 1973. The Impact of Film, How Ideas Are Communicated Through Cinema and Television, Macmillan Publishing Co., Inc.

[9] Tabrani, P. 1998. Messages from Ancient Walls, Bandung, ITB Publications. 